\title{
Pictorial Imagery, Camerawork and Soundtrack in Dario Argento's Deep Red
}

\author{
Giulio L. Giusti \\ Sheffield Hallam University (UK) \\ E-mail: G.Giusti@shu.ac.uk
}

\begin{abstract}
This article re-engages with existing scholarship identifying Deep Red (Profondo rosso, 1975) as a typical example within Dario Argento's body of work, in which the Italian horror-meister fully explores a distinguishing pairing of the acoustic and the iconic through an effective combination of elaborate camerawork and disjunctive music and sound. Specifically, this article seeks to complement these studies by arguing that such a stylistic and technical achievement in the film is also rendered by Argento's use of a specific art-historical repertoire, which not only reiterates the Gesamtkunstwerklike complexity of the director's audiovisual spectacle, but also serves to transpose the film's narrative over a metanarrative plane through pictorial techniques and their possible interpretations. The purpose of this article is, thus, twofold. Firstly, I shall discuss how Argento's references to American hyperrealism in painting are integrated into Deep Red's spectacles of death through colour, framing, and lighting, as well as the extent to which such references allow us to undertake a more in-depth analysis of the director's style in terms of referentiality and cinematic intermediality. Secondly, I will demonstrate how and to what extent in the film Argento manages to break down the epistemological system of knowledge and to disrupt the reasonable order of traditional storytelling through the technique of the trompe-l'oeil in painting.
\end{abstract}

Keywords: Dario Argento, Deep Red, excessiveness of imagery and sound, American hyperrealism, trompe-l'oeil.

"I had never seen anything like Deep Red. It wasn't the story that stuck with me months, and then years [...], it was the overwhelming experience of it, equal parts visual-vivid colours and bizarre camera angles, dizzying pans and flamboyant tracking shots, disorientating framing and composition, fetishistic close-ups of quivering eyes and weird objects (knives, dolls, marbles, braided scraps of wool) and aural. Deep Red's throbbing progressive-rock score was almost hypnotic, and alternated with a singsong lullaby whose 'la la la la' lyrics grew more gratingly 
ominous with each repetition" (McDonagh 2010, vii). Maitland McDonagh's consideration is a useful starting-point for broadly contextualizing Deep Red within Dario Argento's body of work. The film was co-written with screenwriter Bernardino Zapponi, whose contribution to the horror genre was made working on Federico Fellini's segment Toby Dammit in Histoires extraordinaires (1967), a three-episode film inspired by the tales of Edgar Allan Poe (Jones 2004, 63). In Deep Red, Argento still relies on the consolidated narrative formula of his directorial debut The Bird with the Crystal Plumage (L'uccello dalle piume di cristallo, 1970), which was firstly pioneered by Italian horror director Mario Bava in his 1962 proto-giallo, The Girl Who Knew Too Much (La ragazza che sapeva troppo). As Peter Bondanella (2009, 375) has argued, the typical Bava-Argento giallo formula centres on an amateur detective who is usually an eyewitness to a murder and whose unreliable sight and subsequent inability to take the distance from the crime manage to lead him or her to an initial misleading conclusion. Hence, the narrative in both The Bird with the Crystal Plumage and Deep Red is based on the fragmented memory of the male protagonist relative to what really happened, and the plots are impressively convoluted until the final denouement and the revelation of the serial-killer's identity. While Sam Dalmas in The Bird with the Crystal Plumage is not initially aware that the black-gloved man in the art gallery is not the attacker but is actually defending himself from his psychotic wife, Marc Daly in Deep Red sees the face of the female killer reflected in a mirror without realizing it.

Despite the aforementioned narrative similarities with The Bird with the Crystal Plumage, Deep Red constitutes a turning point within Argento's career in terms of style and technique. Starting from Deep Red, in fact, the Italian horrormeister experienced a growing interest in the exploration of new professional devices. This allowed Argento to develop his mature cinematic language and technical ability, which became the trademark of the director's work up to the mid-1980s. In The Bird with the Crystal Plumage, for example, Argento still alternates between the serial-killer's POV while striking, represented with long focal length lenses, that of the eyewitness while investigating, represented with standard lenses, and that of the victims being chased, represented with wide angles (Crispino 2008, 195). In addition, the director's omniscient gaze emerges in the final sequence of the film. After the alleged killer has committed suicide, Sam Dalmas goes in search of his fiancée Julia, who has disappeared from the scene of the crime and has been kidnapped by the real murderess. The camera follows Sam in high angle shot and slowly zooms out from the long shot to 
the extreme long shot of the man standing near a building. Then, the camera progresses with a tilt movement from bottom to top that is followed by a pan movement from right to left on the rooftops along the Lungotevere Flaminio in Rome, until it eventually zooms in to reveal the not-yet-discovered place where Julia is held prisoner. By contrast, in Deep Red, Argento constantly disrupts the perception of the audience by moving the camera back and forth and alternating any omniscient shot with a specific POV without discernible pattern. Such a strategy embodies a violation of the classical narrative form typical of the filmmaker's directorial debut with a subsequent failure to motivate cinematic space and time by cause-effect logic (McDonagh 1994, 113). A typical example of this cinematic technique is evident in the opening sequence of the film, in which psychic Helga Ullmann provides a demonstration of her telepathic gift before sensing the presence of a killer among the public of the conference on parapsychology. In the sequence, "accustomed to playing the part of the passive spectator, we suddenly find ourselves occupying the position of the object of our scopophilic desire [...] disrupting our comfortable one-way relationship with the screen" (Gallant 2001a, 15). As soon as the sequence begins, the camera is immediately aligned with the non-diegetic audience's gazes, "walking into the building, through an anteroom and past a hat check guy and a ticket attendant" (Grainger 2001, 116). The peculiarity of this sequence is that the two men at the conference's entrance door do not seem aware that anyone is walking past them. As the big red theatre drapes leading into the conference hall violently open, the camera-audience passes through. As the sequence progresses, there is a constant slippage between the non-diegetic and the diegetic spectator and these apparent POV shots are disrupted by a variety of angles taken from all over the theatre and ranging from a series of extreme long shots from the various balconies to the high angle shot of Helga and her two colleagues on the stage, although no single individual is in all these places. Then, the camera moves from one spectator to another in close-up, focuses on the back of Helga's head, comes back to the stage and makes an extreme close-up of Helga's mouth as she is drinking a glass of water. It resumes diegetic POV status when Helga addresses the killer, who eventually rises from a seat and eases out of the row. [Figs. 1-10.]

This unconventional use of the camera in Deep Red is, moreover, matched with an innovative use of the soundtrack, especially in the sequences preceding and accompanying the several spectacles of death. While in The Bird with the Crystal Plumage, Ennio Morricone's score consists of a mixture of orchestral tunes in the wake of Bernard Herrmann's work for Alfred Hitchcock's Vertigo (1958) and 
Psycho (1960) and with the addition of jazz tunes in the wake of Miles Davis's work for Louis Malle's Elevator to the Gallows (Ascenseur pour l'échafaud, 1958) and Martial Solal's work for Jean-Luc Godard's Breathless ( $A$ bout de souffle, 1960), in Deep Red the soundtrack is entrusted to jazz musician Giorgio Gaslini, but it is added to by some instrumental pieces from the progressive rock band Goblin (Lucantonio 2008, 215-216). In certain extended scenes, such as Marc's visit to the "house of the screaming child," this throbbing downtown jazz crossed with a funk-jam component completely replaces the dialogue as the aural component of the imagery. In the ten-minute-long sequence in which Marc goes to the abandoned villa to investigate, he does not utter a single word while he observes and tries to capture all essential details of the solution to the case. Accompanied by the Goblin's progressive rock soundtrack, the whole sequence is conceived as a film within a film. Each one of Marc's steps is followed in detail, and it seems that Argento is presenting the effective time it would take to explore such a place in reality. As a result, Deep Red becomes the first example within Argento's body of work in which a remarkable excessiveness of images and sound takes place. Although this excessiveness may partly derive from the director's adherence to the tradition of the Italian giallo, which tended to impart a certain aesthetic pleasure by an effective use of editing, music and sound during their various murder sequences, it is undeniable that in Deep Red such a technique achieves one of the most effective and sophisticated aural-visual impacts of Argento's career and makes "the film exceptional in its musical violence, its violation of the logic of the suspense genre, and in the visceral character of the violence depicted" (Smuts 2002).

\section{Hyperrealist Images and Soundtrack: Endoscopy and the Snorkel Camera}

Although fully pertinent, this consideration of a remarkable excessiveness of images and sound in Deep Red, as identified by previous scholarship, is somehow reductive in terms of medium-specific strategies as it does not take into account another fundamental aesthetic aspect within the film. I refer to Argento's use of a specific art-historical repertoire, namely the appropriation of pictorial references and techniques, which - by the director's own admission have been a constant source of inspiration for him and regularly play a large role in defining the film's stylistic structure and effectiveness. On the one hand, such pictorial repertoire in Deep Red fully combines with the excessiveness of images 
and sound as identified by existing literature, and contributes to the focus on the aesthetic composition of the related sequences through diegesis and tableau vivant, while on the other hand, these pictorial references and techniques allow us to undertake a more in-depth analysis of Argento's style in terms of influence, referentiality, and cinematic intermediality.

In light of this statement, we may argue that such a sophisticated interplay of artistic imagery, complex camerawork and disjunctive soundtrack in Deep Red is applicable to a number of sequences, including the one anticipating Helga's gruesome murder by the serial-killer and introducing the audience to the murderer's childish and macabre gadgets. The sequence begins with the closeup of a marble, which causes a dollhouse cradle to tip over. Goblin's pressing progressive rock soundtrack of the credit sequence resumes and Argento displays a number of child's toys belonging to the serial-killer in extreme closeup. Suddenly, the audience witness a swirling and uninterrupted pan over the murderer's childish and macabre collection, all given sinister significance by the camera's relentless gaze. The camera then passes over a red yarn voodoo doll with her stomach stuck with needles, a drawing of a woman being stabbed by an outsized knife, a metal warrior, a wool plait, a naked baby doll that is taken by the black-gloved hand of the killer, a red clay demon, a series of marbles, and two slender switchblade knives. ${ }^{1}$ [Figs. 11-19.] There is eventually a cut to the extreme close-up of the murderer's eye gazing blankly into the camera, ringed with black eye make-up. [Fig. 20.]

As Aaron Smuts (2002) has discussed, the sequence is "intended to give the audience some insight into the lunatic's mind, but given the unexpected prominence of the music and the practically characterless images, it more effectively associates the sounds of Goblin with an abstract insanity." More importantly, Argento's concern in the sequence has nothing to do with narrative progression. Rather, what becomes fundamental is the process through which the effect of tension and terror is created. As Argento has admitted, "the sequence was mainly inspired by hyperrealism in painting and its icy atmospheres [...]. I was particularly interested in representing my characters in hyper realistic situations, as if they were frozen in a picture" (Giusti 2010, 493-494, translation mine). ${ }^{2}$ The

1 A similar ritual of death is repeated before the murder of novelist Amanda Righetti, this time showing a ball slamming other marbles, a creepy doll with a braid of wool twisting around her neck, and the black leather gloves of the serial-killer.

2 Original quotation: "nella sequenza mi sono principalmente ispirato alla pittura iperrealista americana e alle sue atmosfere gelide [...], in particolare, mi piaceva l'idea di rappresentare i miei personaggi [...] in situazioni [...] iperrealiste, fredde, gelide, congelate come in un quadro." 
word hyperrealism or photorealism in art was coined by American author and art dealer Louis K. Meisel in 1968 and appeared in print for the first time in 1970, in a Whitney Museum catalogue. It refers to the art movement that developed from pop art and as a counter to abstract expressionism between the late 1960s and the early 1970s in the United States and that developed throughout Europe from the early 1980s (Meisel 1980, 12). In his exploration of the movement's evolution through the 1990s, Photorealism at the Millennium (2002), Meisel reminds us that since the late 1960s hyperrealism has consisted of the accurate and detailed exploration of the physical and verifiable properties of the objects depicted through the medium of photographic sources. At the same time, this depiction of contemporary subject matter is not only based on photographic sources, but is also blatantly and unapologetically photographic in style. As since the late 1960s the dominant techniques of the art movement have consisted of taking a series of pictures with a camera. Once the photo was developed, usually onto a photographic slide, the artist systematically transferred the image from the photographic slide onto canvas. The resulting images were often direct copies of the original photo, although they were usually larger and sharper than the original reference (Meisel 1980, 12-24). Likewise, in the sequence Argento relies on early hyperrealist (re)sources to provide the most accurate perception of reality through the ubiquity of the camera and maximize such reality in size to create a highly sensorial effect and reveal beneath the surface of every single object a new aesthetically intrinsic dimension.

This is not the first time Argento overtly draws on hyperrealist techniques. In the final sequence of Four Flies on Grey Velvet (Quattro mosche di velluto grigio, 1971), the Italian horror-meister adopted a hyperrealist effect through the use of a technologically advanced high-speed camera to show the murderer's death in a car accident. This is the Pentazet, a German camera that consumes 30,000 frames per second, but when run at normal theatrical speed shows the image in a wholly different temporal register (Lucantonio 2003, 13; Grimaldi 2008, 262; Pugliese $2011,17)$. Yet, it is not slow motion as the image does not drag or shudder. Thus, an accident that normally would last a few seconds is turned into a hyperbolic sequence of death in which every single detail, from the killer's face to the glass shimmering, is explored to the extremes (Needham, 2002). However, while in Four Flies on Grey Velvet this hyperrealist sequence of death is a specific case of elaborate camerawork within the film's more conventional visual tropes, in Deep Red, Argento develops his use of technology on a regular basis. In the sequence displaying the serial-killer's gadgets in particular, Argento was inspired by 
endoscopy, which is a minimally invasive diagnostic medical procedure used to assess the interior surfaces of an organ by inserting a tube into the body (Pugliese $2011,17)$. He used the Snorkel, a thirty centimetres flexible tube that was directly applied to the camera, at the top of which he placed a mirror reflecting the framed object that was instantaneously reflected inside the tube by a series of prisms that were placed in an oblique position in order to be easily exposed in the film (Maiello 2007, 95; Grimaldi 2008, 262). Moreover, because of their subject matter and the technical level of sophistication with which they are represented on the screen, these killer's gadgets show close resemblance to Charles Bell's hyperrealist canvasses of marbles and vintage toys of the early 1970s [Figs. 2122], in whose work the manipulation of size through the use of the camera lens was a defining feature from the 1970s onwards. With the camera, Bell could light and set up a still life on a small platform in any way he desired, photograph it in many different focuses and exposures, and eventually project it to any size and scale before deciding how the final painting would look. He decided that the effective scale would be between six and twelve times life size. Thus, by regularly increasing the size of any object, Bell was able to involve himself in the intrinsic reality of the object itself, including colour and the potentialities of light, such as light distorted by diffusion, light as reflection, and light as transparency (Geldzahler 1991, 34; Meisel 1993, 35-36). Likewise, Argento's sequence is more focused on showing a camera-mediated gaze rather than what the human eye can perceive in the same circumstances. As Edward Lucie-Smith $(1979,12)$ has pointed out, the camera has monocular vision while our own vision is binocular. The monocular way of seeing produces many of the aberrations we notice when we look at a photograph, although these vary in turn with the actual choice of lens. The human eye operates more flexibly than the camera, but Argento does nothing to compensate such distortions. Indeed, he chooses to emphasize them to make the audience aware of the exact nature of his source material.

\section{Hyperrealist Images and Soundtrack: the Murder "Set-Pieces"}

Other valuable examples relying on the distinguishing pairing of hyperrealist images and soundtrack in the film are visible in the sequences regarding the elaborate murder "set-pieces" which Donato Totaro $(2003,162)$ has defined in the following terms: "a situation or set of actions where narrative function [...] gives way to 'spectacle' [and] the scene plays on far longer than is strictly necessary for 
the narrative purposes". In this regard, the first effective characteristic of Deep Red's fête sanguinaire is represented by the diegetic and non-diegetic musical accompaniment, which serves as a powerful transition device that both anticipates and accompanies every gruesome act of bodily violence. According to Smuts (2002), the ominous children's lullaby that is played on a hand-held tape recorder before every act of murder in the film is first and foremost aimed at alerting the audience to the fact that another homicide is going to occur. In the attempted murder of Marc and the murder of novelist Amanda Righetti, this hand-held tape recorder is displayed in a hyperrealist extreme close-up, so that the audience can see the tape running slowly and be hypnotised by the creepy and repetitive sound. [Figs. 23-26.] During the film, Professor Giordani explains the murderer's motivation for playing the song in question prior to each attack. According to Giordani, the serial-killer must have suffered from some traumatic episode in the past and must recreate a certain aspect of the original event in the present. At the same time, as Smuts (2002) has suggested, Argento tries to place the audience in a similar position to the killer by playing this song before any act of murder.

While the use of the diegetic lullaby can be said to be motivated by narrative purposes, the use of the macabre toys that precede both Amanda's and Giordani's death may be interpreted from a different perspective. [Figs. 27-28.] The serialkiller in Deep Red is first of all a sadist who terrifies her victim-to-be in a tense game of cat and mouse. Before Giordani is killed, for example, a cackling mechanical doll is set loose in his study, walking towards him. This interference clashes with the logic of the story. The doll comes from the door on the right, while the murderer is already in the room waiting for her victim from behind. The consequence of this procedure is a type of writing that completely lacks in a real connection between cause and effect and is merely intended to disrupt the audience's expectations by breaking the link between the two. Although there is no particular logic to the action, the image of the broken doll, arms flailing, skull fractured, and mechanical laugh still echoing, is profoundly unnerving and imparts tension to the sequence as a preamble to the murder. More specifically, this strategy is integral to the manner in which the giallo depicts murder set-pieces as heightened spectacles with the aim of interrupting the flow of the narrative in order to produce aural and visual moments of beauty and evocative power (Guins 1999, 141). However, Deep Red's technically accomplished murder set-pieces may also be interpreted according to a more literary-based horror tradition. In particular, the ways Argento's murder scenes are choreographed and organized in the film are very close to the ones staged in the Grand-Guignol, the French red- 
light district theatre of the erotic, the horrific, and the morally dubious. As Louis Paul $(2005,10)$ has discussed, the Grand-Guignol did not work on the tradition of supernatural horror, but rather explored the horror of contemporary cities in graphic detail and unbelievable cruelty. Of particular interest and relevance to Argento's use of set-pieces in Deep Red was the modality of representing and staging the act of murder as a highly sensational moment, in which violence was played longer than was strictly necessary "in order to squeeze every ounce of tension out of the scene" (Hand and Wilson 2002, 38). In 1931, a French journalist argued that the Grand-Guignol author had to calibrate every single murder scene in order to create a well-crafted timing device, where second by second the mechanism was going to turn until the bomb finally exploded (Hand and Wilson 2002, 47-48). A consequence of the exaggeration of the act of violence was the way every Grand-Guignol actor tended to perform any scene with a series of extremely heightened gestures. In the Grand Guignol, the melodramatic technique of addressing the audience directly was a typical way of slowing down the action. Specifically, every single actor, either murderer or victim, tended to fix his or her gaze on the audience in any violent moment as a strategy in performance practice to manipulate time and increase the viewers' tension. Another method included the interruption of the act of violence in order to move away from the focus and then return to it later, as the pauses and silences were indispensable elements to make the viewers' imagination flow. In Deep Red, the same techniques are achieved through camerawork. As Chris Gallant (2001a, 13) has argued, as far back as The Bird with the Crystal Plumage, the psychopath's POV had become a staple element in Argento's work, initially using both a hand-held tracking shot and a steady cam. In The Cat o' Nine Tails (Il gatto a nove code, 1971), the Italian director improved this technique by delivering an unsettling variation of the same formula. In the film, the killer's POV is sometimes interrupted by a close-up of his eyes looking directly at the audience. Indeed, this diegetic interference provokes a note of ambiguity in the relationship between the film and the audience. While the audience is forced into identification with the point of view of the murderer, they are simultaneously stitched into the fabric of the filmic world by becoming the focus of the directorial gaze. In Deep Red, Argento eventually refines this technique of threatened spectatorship. During Amanda Righetti's murder, while the victim is walking through the corridor of her house, an eye stares out from the darkness of an open closet first scrutinising the surrounding area and then staring directly at the camera with a penetrating gaze (Gallant 2001b, 80; Pugliese 2011, 40). 
What really distinguishes Deep Red's spectacle of death from the aforementioned gialli, however, can be found in Argento's ability to show murder as a mere act of artistic creation. This equation - responsibility for which effectively shifts from the director, as behind-the-scenes narrator, to the murderer, as diegetic set designer - is aesthetically and symbolically conveyed with the victims being placed in a position mimicking pictorial iconography and their eventual transformation into objets d'art through the composition of the shot. Specifically, in Deep Red Argento immortalizes his victims in a hyperrealist picture of death by employing a variety of reflecting surfaces, such as glass, metals, and mirrors, and by exploring all potentialities of their lighting effects. Reality and reflection of reality become indistinguishable from one another, and the focus on the latter generates a kind of nightmarish fantasy in spite of rigidly explicit factual details. All murder set-pieces, in fact, end up with the frozen image of the corpses reflected in harsh reflective surfaces, such as the glass of a window in the case of Helga, a reflecting wall in the case of Amanda, and a reflecting desk in the case of Giordani; and in all these cases Argento focuses on the close-up of the martyred corpses and their reflections, creating an optical alignment of both images. [Figs. 27-32.] This optical illusion generated by the alignment of reflecting surfaces also lies at the heart of Richard Estes's hyperrealist reflection series of the 1960s. [Fig. 33.] In this series of canvasses depicting some downtown areas of New York, Estes did not work on the direct depiction of the objects. Rather, he shifted the focus from the objects onto the effects of light and shadow that were generated by their reflections on shining surfaces, such as a car's bonnet, a large-windowed building, a shop window, a telephone booth, or a pool of water in the street. These clean surfaces are the only subjects of the canvasses, and Estes's realities appear distorted, fragmented, and inverted according to their alignment to the shining surfaces. In some examples, a wall divides two scenes, such as the inside and the outside of a bus or of a shop window, causing a juxtaposition of real and reflected images and of images reflected in the reflections of other images. To compose such canvasses, Estes used to stand between two and ten feet from a storefront, which was usually made of glass. Then, he aimed his camera straight up the street to create a single centred vanishing point. Approximately half of the resultant photograph and the subsequent painting was a reflection of the other half (Meisel 1986, 57). Similarly, Argento employed the same effect in Deep Red's final shot of the murderer's death. As soon as the serial-killer tries to kill Marc, her heavy necklace wedges into the elevator shaft decapitating her. The act of decapitation is shot in gruesome detail with the extreme close-up of the 
woman's chain slowly splitting her throat and her mouth secreting a yellowish substance as a result of the process of beheading. Following this, Argento makes a cut to a close-up of Marc's distorted and inverted image reflected in the pool of blood, creating an illusionist effect (Toffetti 2008, 158). [Figs. 34-35.] The shot's richness of visual information is comparable to Estes's canvasses, as the dynamic interplay between the figure, the reflected visual elements, and the dispassionate perfection of the execution enhance each other to create a synergistic balance and tension that give this sequence a highly hyperrealist effect.

\section{The Trompe-l'Oeil: the Invisibility of the Visible Through the Artwork}

The optical alignment of images and their reflections also assumes a crucial role in terms of narrative as it contributes to the final denouement of the story in which the serial-killer's identity is eventually revealed. As Sébastien Bazou has pointed out, “to enter one of Argento's films is to enter a disquieting universe full of signs to decipher [...]. The viewers are at once masters of the game and totally manipulated by it, free to interpret all the signs and symbols presented to them or, on the contrary, free to let themselves be driven along in a ghost train" (2009, translation mine). ${ }^{3}$ Bazou's consideration suggests a cinema centred on the importance of sight, in which both the story and the visual composition of the film are conceived as a unique blend that is able to challenge and stimulate the viewers' ingenuity. This is the case of Deep Red, in which every single detail becomes an indispensable piece that contributes to the whole structure of the film's narrative and visual impact. A typical example of this statement is provided in the sequence in which Marc witnesses Helga's murder from the adjacent piazza and rushes to the woman's apartment to try to help. While walking down a corridor lined with Edvard Munch-style paintings, Marc fails to realize that one of the paintings - in which four ghostly women are painted - is actually a mirror in which the murderer's face can be clearly seen - thereby confusing representation with reality and not realizing the importance of what he saw until it is almost too late. [Figs. 36-39.] As a result, the audience also are drawn to the same mistaken conclusion, particularly as in the sequence the whole of the mirror is visible for only a single frame and the fast dolly shot makes it nearly

3 Original quotation: "entrer dans un film d'Argento c'est entrer avec inquiétude dans un univers de signes à déchiffrer [...]. Le spectateur est à la fois maître du jeu et totalement manipulé, libre de surinterpréter tous les signes et les symboles qui se présentent à lui ou, au contraire, libre de se laisser guider dans un train fantôme." 
impossible to focus on the relevant part of the screen in time to take in the vital detail. At the film's climax, however, Argento gives a clue to the mystery. When Marc returns to Helga's apartment in order to remember what happened, the director zooms in to a close-up on the serial-killer's face, which becomes visible in the mirror together with the painting. [Figs. 38-39.]

Since The Bird with the Crystal Plumage, in which Sam Dalmas tries to solve a series of crimes by codifying the meaning hidden behind an old naïf painting, pictorial repertoire in Argento's cinema has sometimes served to recreate the backbone of the story through artistic images and their possible interpretations. In Deep Red, Argento takes a step forward in this sense by breaking down the epistemological system of knowledge through art and, as a consequence, disrupting the reasonable and discursive order of traditional storytelling through the medium of pictorial iconography. More specifically, the director explicates a paradox, the invisibility of the visible, through the artwork. In the sequence, art confuses Marc and, at the same time, denies full understanding to the audience following the scene by employing the medium of trompe-l'oeil. The trompe-l'oeil is a pictorial technique that aims to trick the eye by making the audience think they are seeing an actual object and not a painted one. In Deep Red, Argento produces the opposite effect in that a tree-dimensional object is perceived as twodimensional. More significantly, in the sequence, Argento manages to convey the narrative trope typical of the giallo formula, which is the fragmented and misleading sight of the eyewitness in relation to the true situation, through the medium of a pictorial technique.

The theme of the short-circuiting of sight that is typical of the giallo formula in the sequence is also achieved through a technically sophisticated combination of complex camerawork and unsettling soundtrack, which seems designed to mobilize the audience's attention and eventually manages to mask the essential detail from sight. As Jean Baptiste Thoret (2003, 83-84) has suggested, the tracking shot in the corridor has the function of directing the viewers' gaze towards the bottom of the frame and does not allow them to make the difference necessary to discover the right sign. If the viewers go back to Helga's murder, they will discover that the serial-killer is reflected in the mirror, but it is almost impossible to see her without using the still frame facility. Moreover, the mirror is positioned at the edge of the frame, so the audience watching the film in a pan-and-scanned version would have even less chance of spotting this pivotal moment. Quite simply, the audience could not possibly be expected to see the murderer and solve the puzzle, as they have not been introduced to the character at this point 
of the story. On the contrary, the murderer's reflection in the mirror acquires the function of isolating the detail from a general context by freezing it in a tableau of watching. As Argento has stated, "the mirror fascinates me because of its power to isolate the detail from its general context. A vision of the whole is sometimes deceiving and misleading for both the character in the film and the audience. The detail shown in the mirror can be distinguished more easily" (Giusti 2010, 494, translation mine). ${ }^{4}$ Thus, the reflection in the mirror focuses all the audience's attention on what Gary Needham (2002) has identified as the punctum, which is a consequential detail that punctures the eye, adding something that the miseen-scène and narrative cannot contain and foretell. A vision of the whole can deceive and mislead both the protagonist and the viewers, but any single detail that is projected into a mirror can be spotted more easily. In Deep Red, the simple act of seeing is not sufficient to full understanding. Reality as it is revealed to the audience is a riddle that must be analyzed constantly and broken down to the smallest detail to ensure a solution.

\section{Conclusion}

Deep Red is a typical example within Argento's body of work to show a sophisticated interplay of artistic imagery, complex camerawork, and unsettling soundtrack. In this respect, as this article has demonstrated, artistic imagery becomes an indispensable piece that contributes to the whole structure of the film's narrative and visual impact. On the one hand, artistic imagery reinforces Deep Red's stylistic and technical innovation through the medium of a consolidated pictorial repertoire. Specifically, Argento combines the techniques of the close-up and extreme close-up, and the progressive rock soundtrack with an artistic subject matter that is typical of hyperrealist painting of the late 1960s and early 1970s. The relationship to the hyperrealist painting of the late 1960s and early 1970s in the film is clear through the director's use of the Snorkel camera in the depiction of the killer's toys which is reminiscent of Charles Bell's paintings of vintage toys and marbles. In a similar manner, Argento's use of lighting in the multiple murder set-pieces is comparable to the light effects of Estes's paintings of the 1960s. The photographic-type accuracy with which Argento focuses on surfaces encourages the audience to pay full attention to

$4 \quad$ Original quotation: "ciò che mi affascina dello specchio è il suo potere di isolare il dettaglio dal suo contesto generale. Una visione dell'insieme a volte inganna e svia sia il personaggio del film sia lo spettatore. Il dettaglio proiettato nello specchio si distingue con più facilità.” 
the aesthetic and intrinsic qualities of the objects represented rather than to the narrative progression of the sequences involved. Apart from the aesthetic and symbolic values of artistic imagery in defining Argento's stylistic and technical effectiveness, art-historical repertoire also assumes an essential role in terms of (meta)narrative. Argento utilizes the pictorial device of the trompe-l'oeil in order to mislead both the film's protagonist and the audience about the crucial detail that would lead to the resolution of the case. Thus, the giallo theme of the amateur detective's misleading sight while witnessing a crime is symbolically reiterated by the effect of a pictorial technique. For all these qualities, Deep Red is the first of Argento's fêtes sanguinaires in which artistic imagery, narrative, and style come together in a highly powerful blend.

\section{References}

Bazou, Sébastien. 2009. Dario Argento: La traversée des apparences. [Dario Argento: Crossing the Appearances], Artefake: documentations des arts magiques. http://www.artefake.com/spip.php?article328. Last accessed 28. 10. 2015.

Bondanella, Peter. 2009. A History of Italian Cinema. New York, London: Continuum.

Crispino, Francesco. 2008. Riflessi in un occhio d'Argento: la messa in scena. [Reflections in Argento's Eyes. The Mise-en-scène]. In Argento vivo: il cinema di Dario Argento tra genere e autorialità [Argento Vivo: Dario Argento's Cinema between Genre and Authorship], ed. Vito Zagarrio, 193-200. Venezia: Marsilio Editori.

Gallant, Chris. 2001a. Quoting the Raven: Philosophies of Composition and the Female Corpse as Object of Art: The Influence of Edgar Allan Poe. In Art of Darkness: the Cinema of Dario Argento, ed. Chris Gallant, 11-19. Godalming, UK: FAB Press.

Gallant, Chris. 2001b. Threatening Glances: Voyeurism, Eye-Violation and the Camera: from Peeping Tom to Opera. In Art of Darkness: the Cinema of Dario Argento, ed. Chris Gallant, 75-83. Godalming, UK: FAB Press.

Geldzahler, Henry. 1991. Charles Bell: the Complete Works 1970-1990. New York: Harry N. Abrams Publishers.

Giusti, Giulio Luciano. 2010. Turbamenti figurativi: conversazione con Dario Argento. [On Artwork: Conversation with Dario Argento], Filmcritica no. 609/610 (December): 490-496. 
Grainger, Julian. 2001. Deep Red. In Art of Darkness: the Cinema of Dario Argento, ed. Chris Gallant, 115-125. Godalming, UK: FAB Press.

Grimaldi, Antonello. 2008. Generazioni di cineasti a confronto. [Directors and Their Generations: A Comparison]. In Argento vivo: il cinema di Dario Argento tra genere e autorialità [Argento Vivo: Dario Argento's Cinema between Genre and Authorship], ed. Vito Zagarrio, 261-264. Venezia: Marsilio Editori.

Guins, Ray. 1996. Tortured Looks: Dario Argento and Visual Displeasure. Necronomicon: the Journal of Horror and Erotic Cinema vol. 1: 141-153.

Hand, Richard, J. and Michael Wilson. 2002. Grand-Guignol: The French Theatre of Horror. Exeter: University of Exeter Press.

Jones, Alan. 2004. Profondo Argento: The Man, the Myths and the Magic. Godalming, UK: FAB Press.

Lucantonio, Gabrielle. 2003. Il cinema secondo Argento. [The Cinema According to Argento]. In L'eccesso della visione: il cinema di Dario Argento [The Excess of Vision: the Cinema of Dario Argento], eds. Giulia Carluccio, Giacomo Manzoli and Roy Menarini, 9-25. Torino: Lindau s.r.l.

Lucantonio, Gabrielle. 2008. Sempre nuovi orizzonti sonori: la musica. [New Horizons in Music]. In Argento vivo: il cinema di Dario Argento tra genere e autorialità [Argento Vivo: Dario Argento's Cinema between Genre and Authorship], ed. Vito Zagarrio, 215-223. Venezia: Marsilio Editori.

Lucie-Smith, Edward. 1979. Super Realism. Oxford: Phaidon Press.

Maiello, Fabio. 2007. Dario Argento, confessioni di un maestro dell'horror. [Dario Argento: Confessions of a Master of Horror], Milano: Alacrán Edizioni.

McDonagh, Maitland. 1994. Broken Mirrors/Broken Minds: the Dark Dreams of Dario Argento. New York: A Citadel Press Book-Carol Publishing Group.

McDonagh, Maitland. 2010. Broken Mirrors/Broken Minds: the Dark Dreams of Dario Argento. $3^{\text {rd }}$ ed. Minneapolis, London: University of Minnesota Press.

Meisel, Louis K. 1980. Photo-Realism. New York: Harry N. Abrams, Inc. Publishers.

Meisel, Louis K. 1986. Richard Estes: The Complete Paintings 1966-1985. New York: Harry N. Abrams, Inc. Publishers.

Meisel, Louis K. 1993. Photorealism Since 1980. New York: Harry N. Abrams, Inc. Publishers.

Meisel, Louis K. 2002. Photorealism at the Millennium. New York: Harry N. Abrams, Inc. Publishers.

Needham, Gary. 2002. From Punctum to Pentazet, and Everything in Between Dario Argento's Il gatto a nove code (The Cat O' Nine Tails, 1971) and Quattro 
mosche di velluto grigio (Four Flies on Grey Velvet, 1972). Kinoeye vol. 2 no. 11. http://www.kinoeye.org/02/11/needham11_no2.php. Last accessed 28. 10. 2015.

Paul, Louis. 2005. Italian Horror Film Directors. Jefferson, N.C. and London: McFarland.

Pugliese, Roberto. 2011. Dario Argento. Milano: Il Castoro Cinema.

Smuts, Aaron. 2002. The Principles of Association: Dario Argento's Profondo rosso (Deep Red, 1975). Kinoeye vol. 2 no. 11. http://www.kinoeye.org/02/11/ smuts11.php. Last accessed 28. 10. 2015.

Thoret, Jean Baptiste. 2008. Dario Argento, magicien de la peur [Dario Argento: Magician of the Fear]. Paris: Cahiers du Cinéma.

Toffetti, Sergio. 2008. Ce n'est pas du sang, c'est du rouge: Argento e l'arte figurativa. [Not Blood, but Red. Argento and the Fine Arts]. In Argento vivo: il cinema di Dario Argento tra genere e autorialità [Argento Vivo: Dario Argento's Cinema between Genre and Authorship], ed. Vito Zagarrio, 155-159. Venezia: Marsilio Editori.

Totaro, Donato. 2003. The Italian Zombie Film: from Derivation to Reinvention. In Fear Without Frontiers: Horror Cinema Across the Globe, ed. Stephen J. Schneider, 161-173. Godalming, UK: FAB Press. 


\section{List of Figures}

Figures 1-10. Argento's complex camerawork: the sequence of the conference on parapsychology.
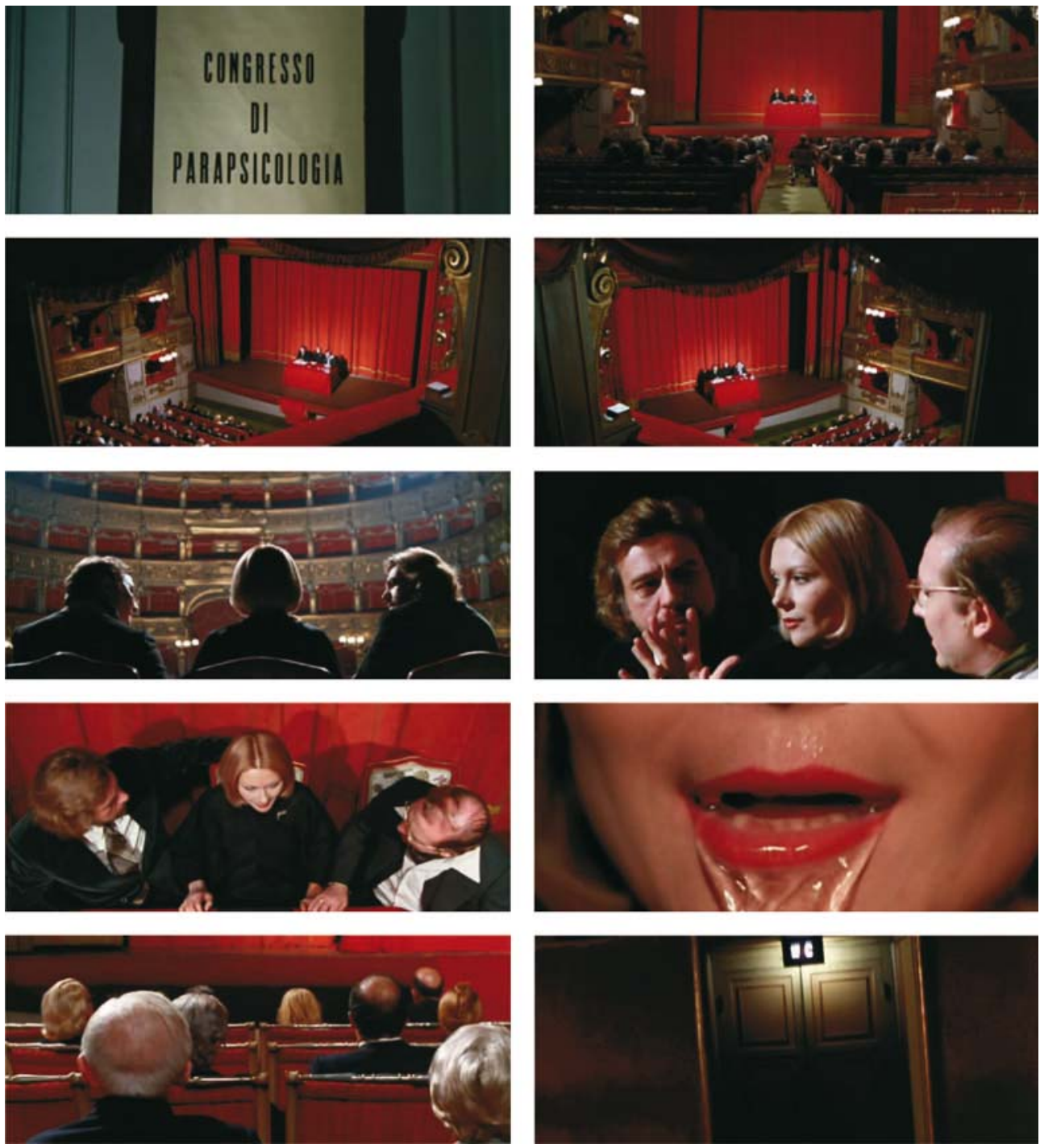
Figures 11-19. The killer's childish and macabre collection. Figure 20. The extreme close-up of the killer's eye.
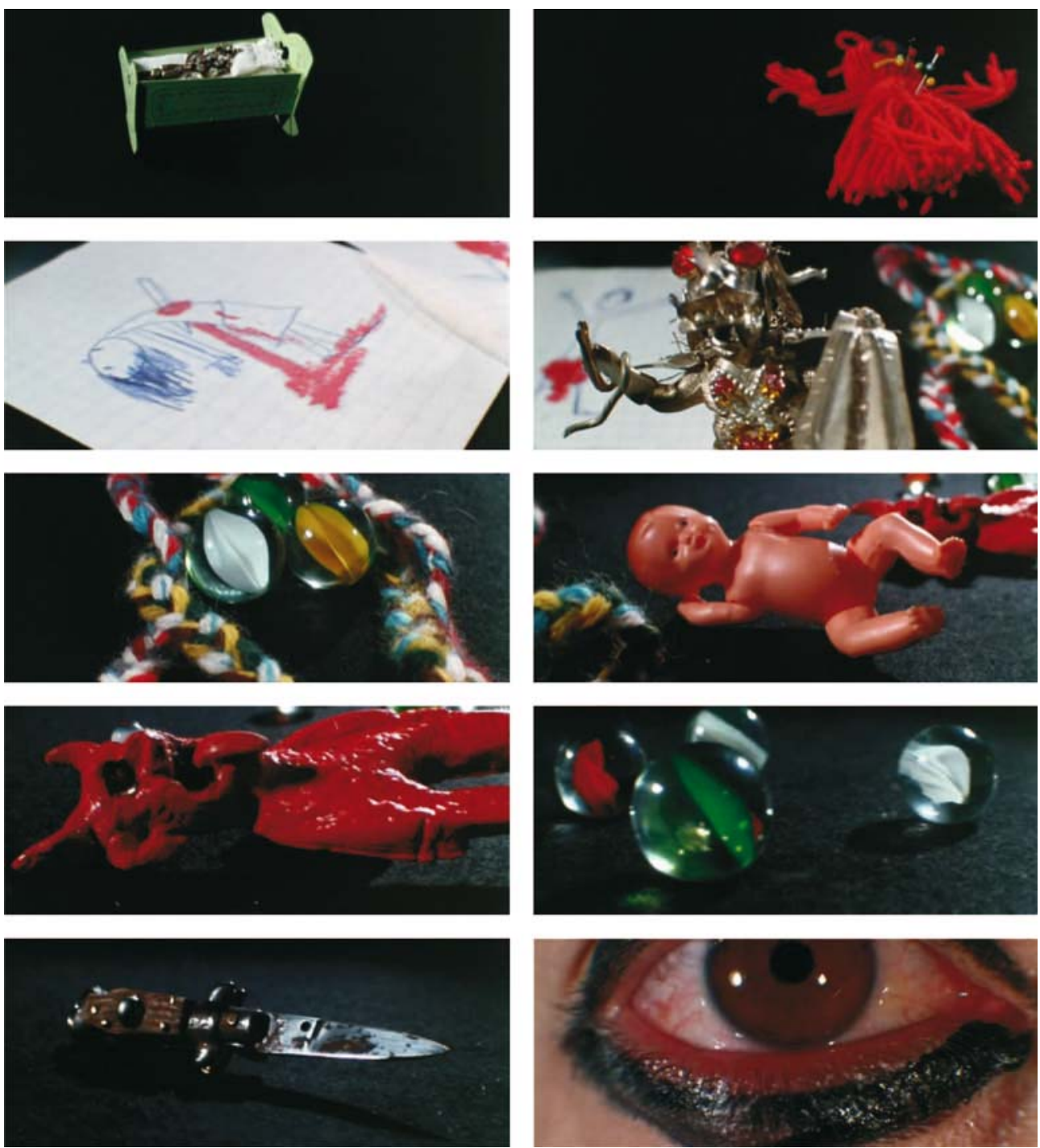
Figures 21-22. Two examples of Charles Bell's art: on the left, Raggedy Ann with Baseball (1971), picture available at http://www.wikiart.org/en/charles-bell/ raggedy-ann-with-baseball-1971; on the right, Tops (1972), picture available at http://www.wikiart.org/en/charles-bell/tops-1972
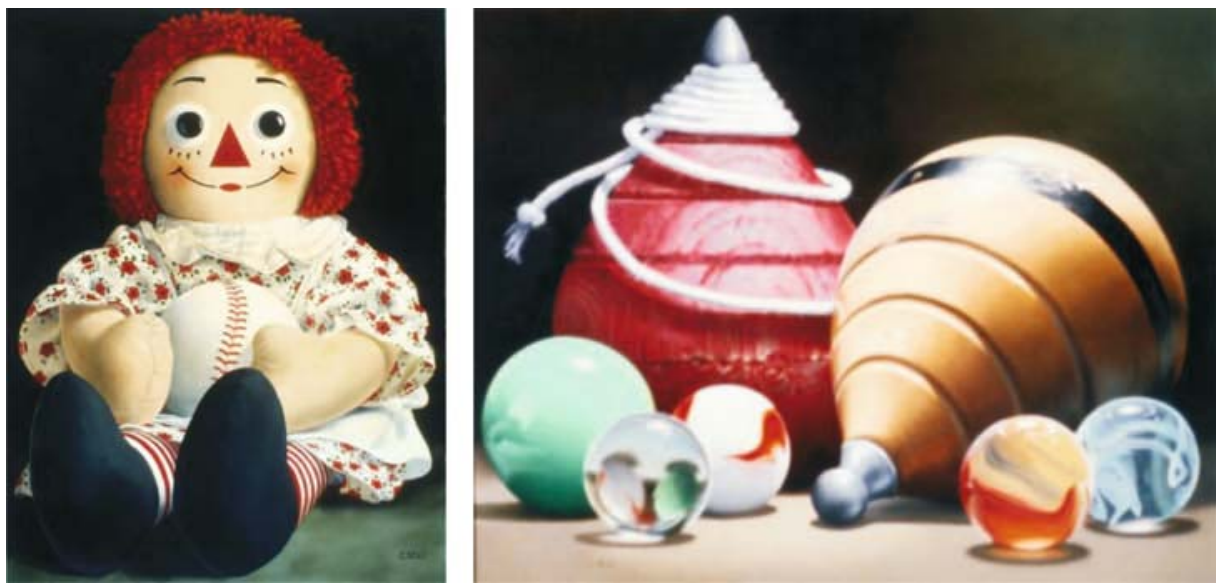

Figures 23-26. The killer's ritual of death: the hand-held tape recorder and the macabre gadgets.
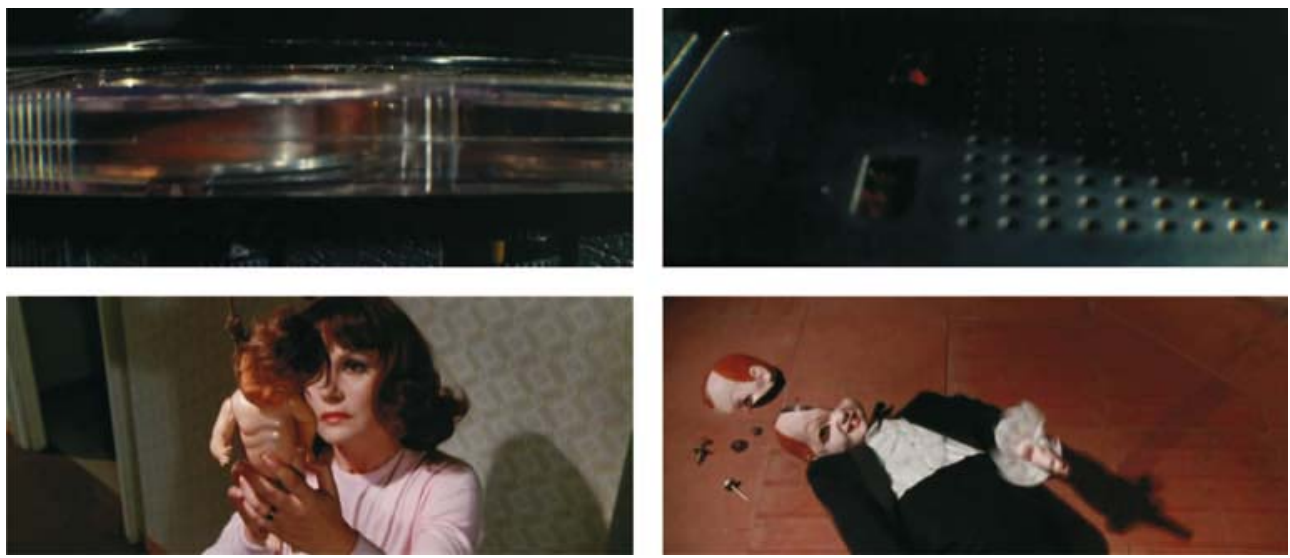

Figures 27-32. The martyred corpses and their reflections.
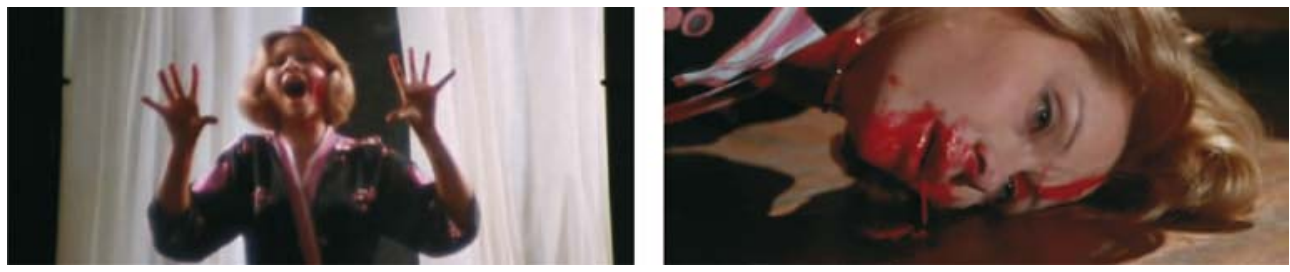

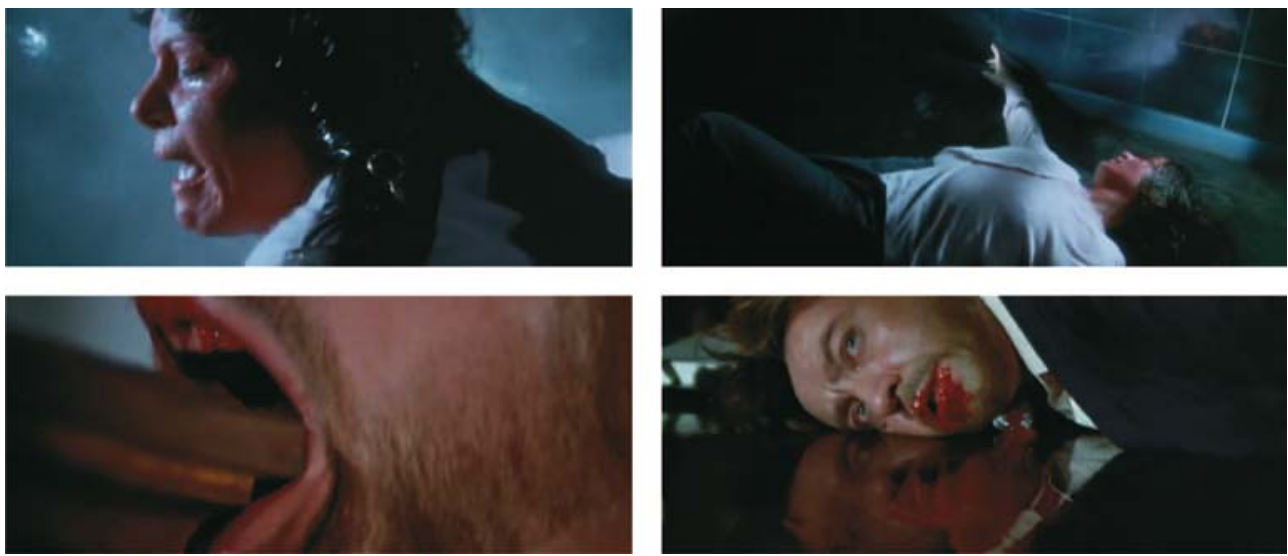

Figure 33. An example of reflections on the work of Richard Estes: Telephone Booths (1967), picture available at: https://www.flickr.com/photos/ campra/9717963791/.

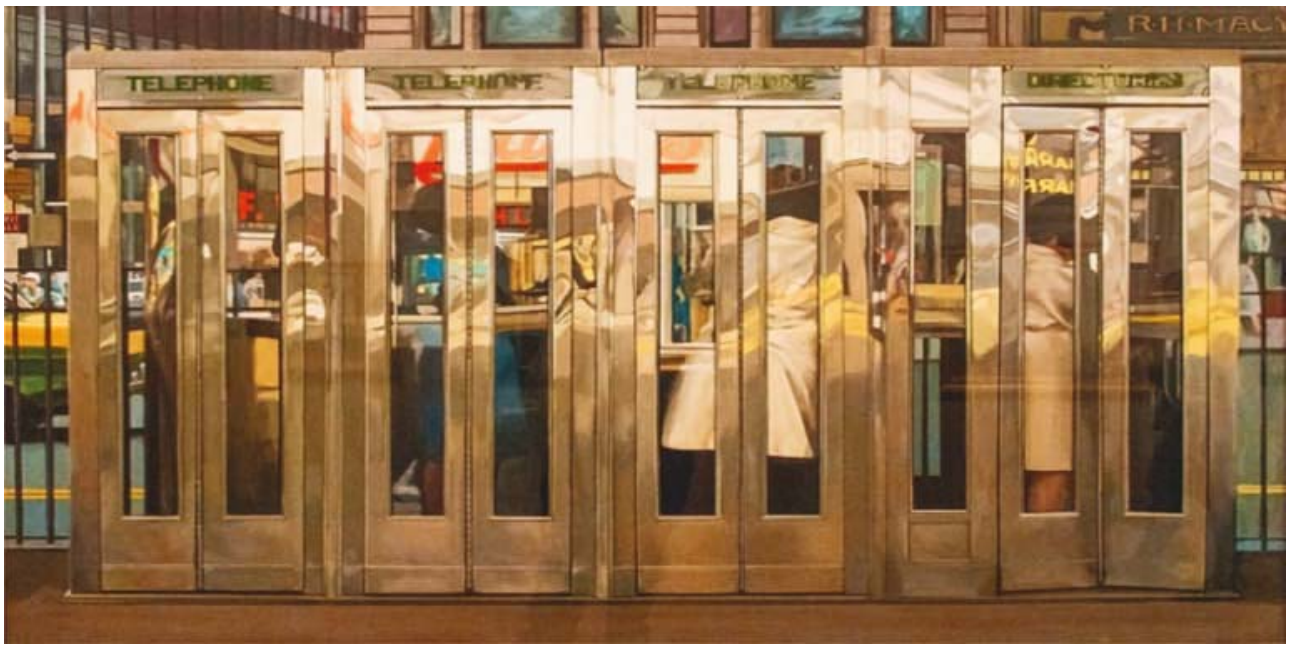

Figures 34-35. The killer's gruesome death.
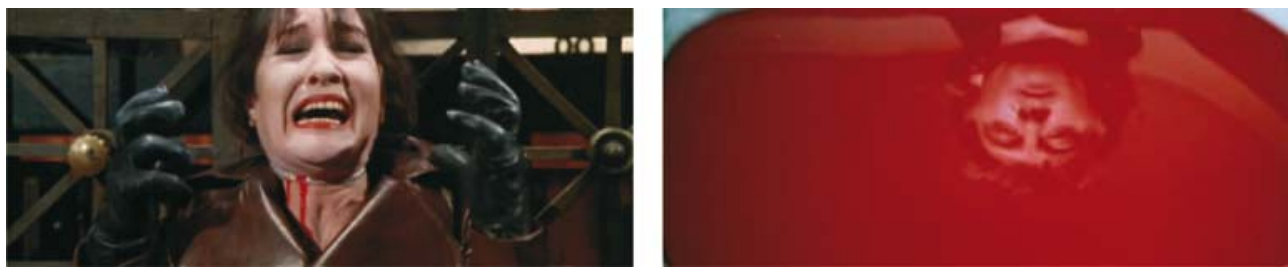
Figures 36-39. Art of deception: the trompe-l'oeil through the mirror.
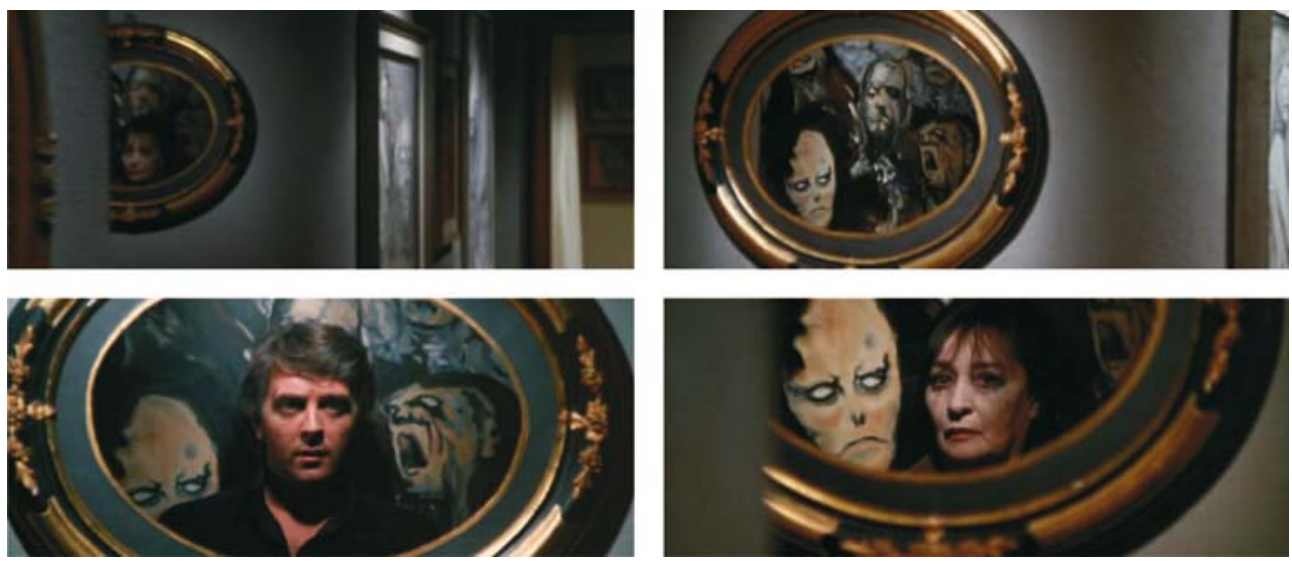